\title{
Rising from the Ashes, Once Again?
}

\author{
The Beirut Port Explosion and International Disaster Law
}

\author{
Silvia Venier*
}

\section{Introduction}

Resilience is nowadays one of the building blocks of the paradigm that guides our efforts to manage disaster situations. Taken from the engineering sector, where it refers to the ability of some materials to be subject to an external stress agent, cope with the strain and react to it by absorbing it or by changing with a minimum disruption, in other fields it remains a rather mysterious concept. Erwig and Simoncini have recently highlighted that resilience poses a set of challenges for (international) law, including that law must understand what resilience to disasters requires and under which circumstances it must be limited. ${ }^{1}$ A sad occasion to test the drawbacks of the narrative of resilience was recently offered by the explosion that devastated Beirut, Lebanon's capital, on 4 August 2020. Along with the cedar, the symbol of eternal life, Lebanon is indeed known and celebrated for its capacity to recover quickly from the difficulties faced. The resilience of the Lebanese is often compared to that of the mythical Phoenician Bird otherwise known as a Phoenix, which never dies and instead emerges from the ashes to survive another day. According to the legend, Beirut is an urban phoenix as it was rebuilt from the ashes seven times. In the aftermath of the Beirut explosion, however, many Lebanese scholars and activists fervently rejected resilience as a concept that is contributing to perpetuating their condition in a context where radical change is instead desperately needed; they all claimed that resilience has already costed too much to their country. ${ }^{2}$

* PhD, Postdoctoral Researcher in Public International Law, Institute of Law, Politics, Development (DIRPOLIS), Scuola Superiore Sant'Anna, Pisa, Italy.

1 Alessia Erwig and Marta Simoncini, 'Underpinning the Role of Law in Disaster Resilience. An Introduction' in Alessia Erwig and Marta Simoncini (eds), Law and the Management of Disasters. The Challenge of Resilience (Routledge 2017) 20.

2 Carmen Geha, Fida Kanaan and Najat Aoun Saliba, 'Breaking the cycle: Existential Politics and the Beirut Explosion' (2020) 12(3) Middle East Law and Governance 357, 36o; Michel D. Landry et al, 'The 2020 blast in the Port of Beirut: can the Lebanese health system "build back better"? (2020) BMC Health Service Research 1, 4; Tess Graham, 'The Costs of Resilience: the Roots and Impacts of the Beirut Blast' (Just Security, 21 August 2020) https://www.justsecurity. org/72122/the-cost-of-resilience-the-roots-and-impacts-of-the-beirut-blast/ last accessed (as 
To appreciate why Lebanese scholars are rejecting the narrative of resilience, we must consider that the Beirut port disaster occurred when Lebanon was facing the worst financial and economic crisis since the $1975^{-1989}$ civil war, with an inflation rate reported at $70 \%$, and pervasive political instability and social unrest, especially since the 'October Revolution' that started in 2019. The situation was further aggravated by the COVID-19 pandemic in early 2020, when the World Bank projected that more than half of the Lebanese population will be living in poverty by the end of 2021. ${ }^{3}$ Many Lebanese consider that the sectarian elites who are ruling the country since the end of the civil war are responsible for the country's political, financial and societal crisis and ask for radical structural reforms. The post-war Ta'if Agreement, adopted in 1989, was indeed 'a careful division of political, material and military power between the warring parties with the explicit aim of eliding responsibility for the war summed up by the slogan 'no victor - no vanquished'. ${ }^{4}$ After the civil war, the reconstruction of Lebanese consociational state has been accompanied by systematic and extensive corruption, as described in detail by Leenders. ${ }^{5}$

An emblematic example of the situation where multiple parties share power without being actually accountable for its use is precisely the location from where the 4 August 2020 explosion originated. The port of Beirut is locally known as the 'Cave of Ali Baba and the 40 Thieves' for the vast amount of state funds that have reportedly been stolen over decades, with allegations that billions of dollars in tax revenue never reached the state treasury and accusations of systematic and widespread bribery to avoid paying customs taxes. ${ }^{6}$ In its review of the port's functioning, the World Bank recently emphasised that this infrastructure 'has evidently failed to guarantee safe and efficient operations'

any subsequent URL) on 16 June 2021; Lynn Fouad, 'Criminal Responsibility and Legal Proceedings in the aftermath of the Beirut blast: throwing (more) dust in the eyes of the Lebanese?' (Science Po Law Review, 25 February 2021) <https://www.revuedesjuristesdesciencespo.com/ index.php/2021/o2/25/criminal-responsibility-and-legal-proceedings-in-the-aftermath-of -the-beirut-blast-throwing-more-dust-in-the-eyes-of-the-lebanese/\#_ftng>.

3 World Bank, 'Lebanon Economic Monitor: the Deliberate Depression' (1 December 2020) 22 <https://documents1.worldbank.org/curated/en/4745516o6779642981/pdf/Lebanon -Economic-Monitor-The-Deliberate-Depression.pdf $>$.

4 John Nagle and Mary-Alice Clancy, 'Power-sharing after Civil War: Thirty Years since Lebanon's Taif Agreement' (2019) 25(1) Nationalism and Ethnic Politics 1, 6. See also Graham (n 2).

5 Reinoud Leenders, Spoils of Truce: Corruption and State-Building in Postwar Lebanon (Cornell University Press 2012).

6 Timour Azhari, 'Beirut Blast: Tracing the explosives that tore the capital apart' (Al Jazeera, 5 August 2020) <https://www.aljazeera.com/news/2020/o8/05/beirut-blast-tracing-the-explo sives-that-tore-the-capital-apart/?fbclid=IwAR3-EA_w5Fgqq_pgkagacDTIfnLOVWDk2y w2vHFd-FthmwDMlgTcOPbFUUo>. 
and has underperformed in its key role as an enabler of economic development at a national level. ${ }^{7}$ According to the World Bank, these failures are a direct result of the port's governance framework that 'reflects the complex political-economic realities, and (...) as a result run counter to many recognized good practices; $; 8$ while the explosion that occurred on 4 August 2020 'clearly illustrates the evident shortcomings of the current institutional set-up as well as the risks emanating from the no-reform scenario.9 ${ }^{9}$ Calls for socioeconomic structural reforms were included in the 18-month recovery plan launched in December 2020 by the European Union (EU), the United Nations (UN) and the World Bank (called ' 3 RF Plan'), which represents the basis for the initial phase of Lebanon's recovery after the 4 August 2020 tragedy. ${ }^{10}$ Along the path to recovery, a crucial element is to ensure justice to the victims of the Beirut port disaster, which appears to be an extremely complex task in light of the weaknesses of the Lebanese justice system, including lack of independence and impartiality, frequent violation of due process rules, and immunity claims by the political elite.11

Against this backdrop, this paper aims at investigating to what extent international disaster law is adequately equipped to protect persons throughout the life cycle of an emergency in a context where structural change is needed, such as in the case of Lebanon. First, in relation to the pre-disaster phase, it investigates international obligations to prevent accidents deriving from hazardous substances and to establish emergency preparedness rules to minimise the impacts of disasters; and then, in the post-disaster phase, it focuses on to what

World Bank, 'Reforming and Rebuilding Lebanon's Port Sector. Lessons from Global Best Practices' December 2020) $7<$ https://documents1.worldbank.org/curated/en/8236916o9

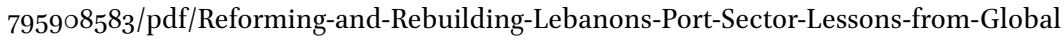
-Best-Practices.pdf>.

8 Ibid., 7. Since the end of the civil war, the port was a national public property managed by a Temporary Committee for Management and Investment of the Port of Beirut, which is not registered as a legal entity. The container terminal management operations are subcontracted to the Beirut Container Terminal Consortium, a joint venture between Lebanon's International Port Management Beirut SAL, the United Kingdom's Portia Peel Ports Limited, and the United States' Logistics and Port Management Americas LLC. See ibid 15 .

$9 \quad$ Ibid.

10 EU, UN and World Bank, 'Lebanon Reform, Recovery, and Reconstruction Framework (3RF)' (4 December 2020) <https://eeas.europa.eu/sites/default/files/lebanon_3rf_report _combined-121420.pdf >.

11 Tess Graham, "Red Lines' in Beirut Blast Investigation: How Exactly Lebanese Politicians Escape Accountability' (Just Security, 9 March 2021) <https://www.justsecurity.org/75252/ red-lines-in-beirut-blast-investigation-how-exactly-lebanese-politicians-escape -accountability/>. 
extent international disaster law can support victims' search for justice and guide true recovery. ${ }^{12}$ It has to be noted that the pre and post-disaster phases are inherently linked, as a better understanding of a disaster's causes and of its implications is crucial in supporting the victims' search for justice and any recovery framework should consider failures in prevention and preparedness to integrate them into new Disaster Risk Reduction (DRR) plans.

The article is organised in four sections. After briefly outlining the origins of the Beirut port disaster and its catastrophic impacts (second section), it highlights the failures in prevention, emergency preparedness and response in light of relevant international obligations and standards, including the lack of a coherent and comprehensive DRR framework (third section). The opportunities to ensure remedies to the victims of the Beirut port disaster and international guidance on disaster recovery are then considered (third section). The paper concludes with some remarks on the role of international disaster law in enhancing protection in countries where structural shortcomings may dramatically contribute to multi-layered disasters, and where the narrative of resilience may result being counterproductive as it prioritises the ability to absorb shocks, rather than the capacity to implement radical change (fourth section).

\section{The Disaster's Origins and Catastrophic Impacts}

On 23 September 2013, the cargo vessel m/v Rhosus, a Moldovan-flagged ship transporting 2,75o tons of ammonium nitrate in bulk, made a stop in Beirut's port for reasons that, at the time of writing, have still to be confirmed. The Rhosus was registered through the so called "flags of convenience" system, which grants the possibility for an owner to register a ship in a country where enforcement of labour, health, safety and environmental regulations may be rather lax. ${ }^{13}$ The cargo was produced by a fertilizer maker in Georgia and was supposed to be delivered to the Fábrica de Explosivos Moçambique (FEM) in

12 The definitions of the four phases of the disaster management cycle are those adopted by the terminology accompanying the Sendai Framework. UnGA, 'Report of the open-ended intergovernmental expert working group on indicators and terminology relating to disaster risk reduction' (1 December 2016) UN Doc A/71/644; UNGA, 'Sendai Framework for Disaster Risk Reduction 2015-203o' (23 June 2015) UN Doc A/RES/69/283.

13 Laleh Khalili, 'Behind the Beirut explosion lies the lawless world of international shipping' (The Guardian, 8 August 2020) <https:/www.theguardian.com/commentisfree/2020/ aug/o8/beirut-explosion-lawless-world-international-shipping->. 
Matala, Mozambique, which is allegedly part of a network of companies with connections to Mozambique's ruling elite that have been investigated for illicit arms trafficking and supplying explosives to terrorists. ${ }^{14}$

Upon inspection in Beirut, the ship was impounded by the Lebanese authorities and forbidden from sailing, most probably due to either unpaid port fees or ship defects, or both. ${ }^{15}$ It was then abandoned by its owners, who declared bankruptcy, and the majority of the crew was repatriated, while only the master and a few other persons remained on board until they were authorised to disembark 10 months later. ${ }^{16}$ According to the Lebanese press, court documents indicate that the official decision from the Urgent Matters judge that permitted the crew to disembark also authorised the Lebanese Ministry of Public Works and Transportation to dry-dock the ship, while stating that the ship was carrying 'dangerous material that had to be stored in appropriate conditions and under the responsibility of the Ministry of Transportation. ${ }^{17}$

Ammonium nitrate is a rather cheap and relatively easily obtainable crystallike white solid, which is made in large industrial quantities and used either as a source of nitrogen for fertilizer or to create explosives for mining. While on its own it is relatively safe to handle, if stored in large quantities and under unsafe conditions, such as in proximity to flames, it becomes extremely dangerous. When ammonium nitrate explodes, it can release toxic gases including nitrogen oxides and ammonia gas. Serious industrial accidents have occurred in the past due to ammonium nitrate, including the 2013 explosion of the West Fertilizer Company in Texas in the United States (US) and the 2015 Tianjin port explosion in China. Ammonium nitrate has been used as a domestic terrorist weapon in the Oklahoma City bombings in the US in 1995 and the Oslo summer camp bombings by Norwegian far-right extremist Anders Behring Breivik in 2011. When the Rhosus was impounded, the ammonium nitrate that was part of its cargo was confiscated by Lebanese authorities and stored in

14 The international investigative journalists' team Organized Crime and Corruption Reporting Project (OCCRP) provides details on the ship ownership and the clients of its cargo. OCCRP, 'A Hidden Tycoon, African Explosives, and a Loan from a Notorious Bank: Questionable Connections Surround Beirut Explosion Shipment' (21 August 2020) <https://www .occrp.org/en/investigations/a-hidden-tycoon-african-explosives-and-a-loan-from-a -notorious-bank-questionable-connections-surround-beirut-explosion-shipment >.

15 Ibid.

16 Charbel Dagher and Christine Maksoud, 'm/v Rhosus - Arrest and Personal Freedom of the Crew' (2015) 11 The Arrest News 1, 3.

17 Muriel Rozelier, 'Explosion au port du Beyrouth: qui est responsable?' (Le Commerce du Levant, 6 August 2020) <https://www.lecommercedulevant.com/article/29998-explosion -au-port-de-beyrouth-les-responsables-cherchent-un-bouc-emissaire >. 
the port's Hangar 12 in completely unsafe conditions, while the ship remained in the port where it finally sank in 2018. Over the following six years, representatives of Lebanon's customs, military, security agencies and the judiciary repeatedly warned that the ammonium nitrate was unsafely stored in the port's warehouse, but no action was taken. ${ }^{18}$ The last warning was sent only a couple of weeks before the tragic explosion to the President and Prime Minister by Lebanese security services, who feared that the material could be stolen to make explosives. ${ }^{19}$

When on 4 August 2020 a fire broke out near the 2,750 tons of ammonium nitrate stored in the port's Hangar 12, it caused the most powerful non-nuclear explosion in human history, registered as a 3.3 magnitude earthquake and felt as far away as in Cyprus. Over 200 people were found dead and over 6.500 injured, while 300.000 persons were left displaced or homeless due to the damaged homes across the city. ${ }^{20}$ The explosion killed not only Lebanese, but also nationals of other countries, such as Syria, Egypt, Bangladesh, Philippines, Australia, Pakistan, the Netherlands, Canada, Germany and France. The tragic event exacerbated the difficulties caused by the coviD-19 pandemic, as two hospitals were completely destroyed and two others severely damaged. The overriding need to save lives meant that CoviD-19 health protocols could not be precisely adhered to, resulting in a dramatical surge of infections in the aftermath of the explosion. The blast destroyed not only the port, which receives over $6 \circ \%$ of Lebanon's imported goods, but also the city's historic centre and large parts of its densely populated residential and commercial areas, causing extensive damage to buildings and infrastructures within a radius of three kilometres. Food availability and safety were directly impacted, as Lebanon's grain silos were destroyed. The economic impact of the disaster was devastating, with 70.000 workers losing their jobs, while the World Bank estimated the cost of the physical damage to be US $\$ 3.8-4.6$ billion and the economic losses to be US\$ $2.9-3.5$ billion. ${ }^{21}$

18 Baseem Mroue, 'Officials long warned of explosive chemicals at Beirut port' (Associated Press, 8 August 2020) <https://apnews.com/article/virus-outbreak-beirut-ap-top-news -international-news-middle-east-6bec1c8ecb5061bf2dd98107aeb151d9>.

19 OCCRP (n 14).

20 International Federation of Red Cross and Red Crescent Societies (IFRC), 'Case Study: Chemical Explosion Beirut Port' (31 August 2020) <https://media.ifrc.org/ifrc/wp-content/ uploads/2020/12/CaseStudy_BeirutExplosion_TechBioHazardsweb.pdf $>$.

21 World Bank, 'Q\&A: Beirut Rapid Damage and Needs Assessment - August 2020' (31 August 2020) <https://www.worldbank.org/en/news/factsheet/2020/08/30/qa-beirut -rapid-damage-and-needs-assessment-august-2020>. 


\section{International (Disaster) Law and Prevention, Preparedness and Response}

In the aftermath of the Beirut port explosion, UN human rights Special Rapporteurs and Independent Experts emphasised that any investigation on the event should consider Lebanon's international obligations, including those governing the handling of dangerous substances and the right of everyone to information on risks to life and health as enshrined under international human rights law, as well as obligations under international commercial and shipping law. ${ }^{22}$ This section explores to what extent the Beirut port disaster was caused by the failure to adopt adequate prevention measures, as required by international rules and standards on handling hazardous substances (3.1) and to what extent its impacts could have been minimized had international preparedness and response obligations and recommendations been met (3.2). The last sub-section discusses the lack of a comprehensive and coherent DRR framework in Lebanon as contributing to this tragedy (3.3).

\subsection{Failures in Prevention}

International obligations and recommendations on preventing serious accidents deriving from dangerous materials and applicable to the present case are enshrined in a set of instruments pertaining to international maritime safety law (3.1.1), chemical safety and international labour law (3.1.2) and international human rights law (3.1.3). These will be discussed in turn.

\subsubsection{International Maritime Safety Law}

Since ammonium nitrate arrived in the port of Beirut on board a vessel, international obligations related to the safe transport of dangerous goods by sea should be first considered to assess potential responsibilities. The 1974 International Convention for the Safety of Life at Sea (solAs), to which Lebanon is party since 1984 and Moldova since 1999, deals with various aspects of maritime safety and governs the carriage of dangerous goods in packaged form under Chapter vir. These provisions are extended and detailed by the International Maritime Dangerous Goods (IMDG) Code, which was initially adopted as a recommendatory instrument in 1965 and acquired mandatory

22 Office of the High Commissioner of Human Rights (онснR), 'UN human rights experts call for justice and accountability in response to Beirut explosion' (13 August 2020) $<\mathrm{https} / / /$ www.ohchr.org/en/NewsEvents/Pages/DisplayNews.aspx?NewsID=26163\&LangID=E > . 
status in 2002 under the umbrella of the solas Convention. ${ }^{23}$ International obligations within SOLAS cover ammonium nitrate under IMDG Chapter 3.2 in Volume 2. These obligations are relevant to the present discussion as also technical issues, which could refer to the violation of safety requirements related to the transport of the cargo, cannot be excluded among the reasons behind the impoundment of the Rhosus vessel in Beirut by the Lebanese port authorities in $2013 .{ }^{24}$ Lebanese judicial authorities would thus have to investigate whether the Rhosus complied with international obligations on the safe transport of dangerous material and to what extent the lack of compliance determined the ship impoundment.

A set of provisions relevant to the transport of dangerous material by sea are also included in the UN Convention on the Law of the Sea (UNCLOS) Part XII on the Protection and Preservation of the Maritime Environment, which establishes the obligation to take measures to prevent pollution inter alia by minimising the release of toxic, harmful, or noxious substances from land-based sources and the risk of accidents from vessels. ${ }^{25}$ More specifically, pursuant to Article 217 UNCLOS (on Enforcement by flag States) Moldova was responsible for ensuring the Rhosus' compliance with applicable international rules and standards, while pursuant to Article 218 (on Enforcement by port States) Lebanon could have investigated the violation of such rules and could have transmitted the records of such investigation to Moldova and requested the flag State to cooperate. Port State Control, which refers to the practice of inspection of foreign ships in national ports to verify compliance with international rules, originally intended to be a back-up to flag State implementation, results to be extremely effective in enforcing international maritime law. Among the nine regional agreements promoted by IMO to harmonise

23 International Convention for the Safety of Life at Sea, adopted 1 November 1974 (solas); Maritime Safety Committee Resolution MSC.122(75) 'Adoption of the International Maritime Dangerous Goods (IMDG) Code' (24 May 2002). The IMDG has been regularly revised and amended. For an example of a detailed guidance document on the safe transport of ammonium nitrate by sea see Australian Maritime Safety Authority, 'Carriage of Ammonium Nitrate of Class 5.1 (UN1942 \& UN2067) and Class 9 (UN2071) to and from Australia' (2015) <https://maritimecyprus.files.wordpress.com/2016/10/amsa279-carriage -of-ammonium-nitrate.pdf $>$.

24 Legal Action Worldwide (LAW), 'Report on Behalf of Victims of the Beirut Explosion of 4 August 2020' (13 November 202O) <http://www.legalactionworldwide.org/wp-content/ uploads/2020/11/REPORT.pdf $>$ para 24.

25 UN Convention on the Law of the Sea, adopted 1o December 1982, art. 194(3)(a) and (b) (UNCLOS). 
the regional inspection regimes, ${ }^{26}$ Lebanon is party to the Mediterranean Memorandum of Understanding which clarifies procedures for inspection, rectification and detention '[i]n the case of deficiencies which are clearly hazardous to safety, health or the environment.' ${ }^{27}$ It has to be noted that in general the deficiencies that are pointed out during port state control must be verified and resolved by the flag State before the vessel could be released. In the case of the Rhosus however the follow up was most probably not successful, as the ship was abandoned, and its cargo stored in the port. From this moment, it is safe to assume that the hazardous material was under the direct responsibility of the Lebanese authorities who were also aware of its dangerousness. It is thus important to clarify whether any international obligations and standards on handling hazardous material in land-based storage facilities existed that were not complied with, which is the aim of the next sub-section.

\subsubsection{Chemical Safety and International Labour Law}

Chemical safety for land-based storage facilities is mainly regulated at the domestic level, supported by a set of guidelines and recommendations developed by international actors for preventing accidents and limiting negative impacts. ${ }^{28}$ Pasman et al point out that the knowledge of how to keep ammonium nitrate safely stored has existed for long time, and refer to industry recommendations on fire prevention and protection, avoidance of contamination, sufficient separation distance between heaps to avoid sympathetic

26 Imo Resolution A17/Res.862, 'Regional Cooperation in the control of ships and discharges' (9 November 1991) A.682(17).

27 Memorandum of Understanding on Port State Control in the Mediterranean Region (2012) para 3.6.3. Moldova however is not party to any of the regional agreements on Port State Control.

28 Organisation for Economic Cooperation and Development (OECD), 'OECD Guiding Principles for Chemical Accidents Preparedness, Prevention and Response. Guidance for Industry (including Management and Labour), Public Authorities, Communities and other Stakeholders' (OECD 2003 ${ }^{2}$ ). Although no specific enforcement mechanisms are foreseen, both the OECD Working Group on Chemical Accidents and the Inter-Agency Coordination Group on Chemical Accidents monitor the practice of States and recommend improvements. See also the United Nations Environmental Programme (UNEP), 'Guidance on the Development of Legal and Institutional Infrastructures and Measures for Recovering Costs of National Administration for Sound Management of Chemicals' (2015 LIRA Guidance). 
detonation. ${ }^{29}$ International guidance is also available on other related aspects, such as land-use planning and siting of hazardous activities. ${ }^{30}$

Legally-binding instruments adopted at the regional and international levels cover the management of hazardous substances and their waste, but significant differences and gaps exist depending on the type of the substance and on the circumstance of use. ${ }^{31}$ The international legal instruments most directly applicable to the present case are those developed within the auspices of the International Labour Organization (ILO), including the Conventions C17O (Chemical Convention) and C174 (Prevention of Major Industrial Accidents) and related Recommendations and Codes of Conducts. The two Conventions were adopted in the early 1990s and ratified by Lebanon in 2006 and 2005 respectively. ${ }^{32}$ These instruments were classified as up-to-date instruments by the ILO Standard Review Mechanism Technical Working Group in 2017, which emphasised the need to gain more knowledge on the main obstacles to their wider adoption in consideration of the low number of ratifications. ${ }^{33}$ Although the main scope of ILO Instruments is occupational health and safety,

29 Hans J. Pasman et al, 'Beirut ammonium nitrate explosion: Are not we really learning anything?' (2020) Process Safety Progress 1, 1.

30 UN Economic Commission for Europe (UNECE), 'Guidance on Land-Use Planning, the Siting of Hazardous Activities and Related Safety Aspects' (2017) <https://unece.org/ DAM/env/eia/Publications/2017/1735403E_Final_ENG_web.pdf >.

31 Ammonium nitrate falls outside the scope of the regime developed within the UNEP auspices which governs the transboundary movement of hazardous chemicals (Basel, Rotterdam and Stockholm Conventions). Within the ambit of the Stockholm Convention on Persistent Organic Pollutants (adopted 22 May 2001), Lebanon participated in a pilot project for the development of a national implementation plan covering Persistent Organic Pollutants, which could be seen as a good practice in this field. See Republic of Lebanon, Ministry of the Environment, 'National Implementation Plans for the Management of Persistent Organic Pollutants. Final Report 2006' (2006). Ammonium nitrate would instead fall within the UN Economic Commission for Europe (UNECE) Convention on the Transboundary Effects of Industrial Accidents, adopted 19 March 1992, which aims at preventing industrial accidents and at minimizing their impacts, but whose geographical scope of application is Europe (and a few other States) and Lebanon is thus not a party.

32 Convention (No. 170) concerning safety in the use of chemicals at work, adopted 25 June 1990 (C170); Chemicals Recommendation, adopted 25 June 1990 (R177); ILO, Safety in the Use of Chemicals at work: An ILO Code of Practice (ILO 1993); Prevention of Major Industrial Accidents Convention, adopted 2 June 1993 (C174); Prevention of Major Industrial Accidents Recommendation, adopted 2 June 1993 (R181); ILO, Prevention of major industrial accidents (ILO 1991).

33 ILO, 'The Standards Initiative: Report of the third meeting of the Standards Review' (2017) GB.331/LILS/2 <https://www.ilo.org/wcmsp5/groups/public/---ed_norm/---relconf/docu ments/meetingdocument/wcms_587514.pdf>. 
the Conventions also generally aim at protecting the public and the environment and directly operate in the area of domestic policy and legislation.

Some provisions of $\mathrm{C}_{170}$ and $\mathrm{C} 174$ are particularly relevant to the present discussion. The C170 'applies to all branches of economic activities where chemicals are used' (Article 1) and obliges State Parties to establish and periodically review a comprehensive national framework for the safe use of chemicals at work (Article 4), as well as appropriate classification and labelling systems and chemical safety data sheets (Articles 6, 7 and 8). Interestingly, Article 14 on Disposal establishes that ' $[\mathrm{h}]$ azardous chemicals which are no longer required and containers which have been emptied but which may contain residues of hazardous chemicals, shall be handled or disposed of in a manner which eliminates or minimises the risk to safety and health and to the environment, in accordance with national law and practice. The reference to chemicals 'which are no longer required' is rather broad and the abandoned Rhosus cargo may fall within this definition. Furthermore, the ILO has clarified that the obligation on the sound disposal of chemical waste is aimed at protecting not only workers, but also the environment and the general public. ${ }^{34}$ It can be affirmed with some certainty that if public authorities in Lebanon had adhered to this provision and had followed relevant international standards, the Beirut port blast would most probably not have occurred.

The $\mathrm{C} 174$ on Prevention of Industrial Accidents imposes the duty to develop and regularly supervise a coherent national policy concerning the protection of workers, the public and the environment in relation to major installations which handle, dispose or store any hazardous substances in quantities which exceed a threshold, as identified by national legislation. Competent authorities are also required to adopt emergency preparedness measures (as discussed in sub-section 3.2). The ILO Code of Conduct on the Prevention of Industrial Accidents defines 'major industrial installations' as including not only industries but also 'an installation which has on its premises, either permanently or temporarily, a quantity of hazardous substance which exceeds the amount prescribed in national or state major hazard legislation'. Ammonium nitrate is explicitly mentioned among those explosive substances for which national authorities have to make specific arrangements to prevent serious accidents, ${ }^{35}$

34 ILO, 'ILO Instruments on Chemical Safety. Analysis and synergies with other international frameworks on the sound management of chemicals' $(2020)<$ https://www.ilo .org/wcmsp5/groups/public/---ed_dialogue/---lab_admin/documents/publication/ wcms_735655.pdf>. 
but apparently Lebanon has not domesticated this Convention and give effect to its provisions, as found by ILO monitoring mechanisms.

Indeed, State Parties to the ILO Conventions are required to periodically submit reports on their implementation, which are then reviewed by the ILO Committee of Experts on the Application of Conventions and Recommendations (CEACR) and eventually by the Committee on the Application of Standards (CAS). A direct request sent to Lebanon by CEACR in 2010 dealing with the implementation of ILO Conventions, including C17O and C174, noted some significant shortcomings in the domestic legal frameworks and offered specific recommendations. ${ }^{36}$ As far as $\mathrm{C} 170$ is concerned, the CEACR did not comment on the provision most relevant to the present discussion (Article 14 C170), but only referred to Article 13(2)(c) C170 (on obligations imposed upon employers), where it noted that domestic legislation effectively requires employers to 'draw up a rescue plan'. ${ }^{37}$ Looking at the review of $\mathrm{C1}_{14}$, the CEACR noted that the government did not provide information on the application of the Convention but only referred to the management of polluting industries and urged the government 'to take measures to give effect to the Convention.' ${ }^{38}$ It thus appears that Lebanon has not effectively implemented the $\mathrm{C} 174$ at the domestic level, including by adopting adequate legislation on disposing large quantities of hazardous substances. In addition, an audit of the Lebanese legal framework governing Labour Inspection (LI) carried out under the ILO auspices in 2009 noted that ' $[\mathrm{t}] \mathrm{he} \mathrm{LI}$ activities in the country are random and do not follow any clear policy or strategy and the ineffectiveness of the LI is intensified by the absence of collaboration among the different concerned institutions.39

\subsubsection{International Human Rights Law}

Finally, international obligations to take adequate measures to protect the rights to life and health of all persons under a State jurisdiction are enshrined

36 CEACR, Direct Request (CEACR), adopted 2019, published 19oth ILC session (2021) <https://www.ilo.org/dyn/normlex/en/f?p=100o:13100:o::NO:1310o:P1310o_COMMENT _ID:4019618:NO>.

37 Decree $\mathrm{n}^{\circ} 118 \mathrm{o} 2$, Regulating Occupational Prevention, Safety and Health in all Enterprises subject to the Code of Labour (2008) Article $50(5)$. Article 50 requires that chemicals are 'stored in rooms and buildings isolated by fireproofs and thermal insulation walls' and that a low temperature is ensured in the storehouse under paras 2 and 3 respectively.

38 CEACR ( $n_{36}$ ). To the author's knowledge, Lebanon has not adopted a dedicated legal instrument on protection against accidents involving hazardous substances.

39 ILO, 'Lebanon labour inspection audit. Joint outcome on labour inspection' (ILO 2009) <https://www.ilo.org/wcmsp5/groups/public/---ed_dialogue/---lab_admin/documents/ publication/wcms_240159.pdf>. 
under international human rights law. As revealed by the recent practice of the UN human rights treaty monitoring bodies, these include substantive and procedural duties, such as the obligation to adopt, regularly update and supervise the implementation of adequate legislative and administrative frameworks; to ensure that the public is informed of any life or health-threatening risk; to adopt and test emergency response plans, as discussed elsewhere in more detail. ${ }^{40}$ Due to concerns over the legal and illegal disposal of waste originating from the global North in the global South, in 1995 the Commission on Human Rights established the mandate to explore the human rights implications of exposure to hazardous substances and toxic waste, which was expanded in 2011 to cover their whole life cycle and was recently renewed. ${ }^{41}$ The Special Rapporteur on Toxic Waste provided guidance to States on ensuring respect of human rights and protecting against violations committed by third parties by enacting and enforcing adequate legislation, creating effective institutions, enabling people to claim and defend their rights. ${ }^{42}$ Thematic reports by the Rapporteur covered specific issues such as the protection of workers, or the implementation of the rights to information and to access to justice in these contexts. ${ }^{43}$

To sum up, international guidance is available on prevention aspects that have been neglected and have directly caused the Beirut port disasters, such as the proper handling of ammonium nitrate especially when stored in enormous quantities, ventilation and separation from flammables, as well as distance from densely populated areas. International treaties ratified by Lebanon require public authorities to develop an adequate legislative framework to ensure that

40 See Emanuele Sommario and Silvia Venier, 'Human Rights Law and disaster risk reduction' (2018) QIL, Zoom-in 29, 36-46; Silvia Venier, 'Positive Obligations to protect against emergency situations under Human Rights Law', in de Guttry et al (eds), International Law and Chemical, Biological and Radio-Nuclear (СвRN) events. Towards an all-hazards approach (Brill forthcoming 2022).

41 Commission on Human Rights Resolution 1995/81, 'Adverse effects of the illicit movement and dumping of toxic and dangerous products and wastes on the enjoyment of human rights' (1995) UN Doc E/CN.4/1995/81; Human Rights Council (HRC), 'Mandate of the Special Rapporteur on the implications for human rights of the environmentally sound management and disposal of hazardous substances and wastes' (2020) UN Doc $\mathrm{A} / \mathrm{HRC} / \mathrm{RES} / 45 / 17$.

42 HRC, 'Report of the Special Rapporteur on the implications for human rights of the environmentally sound management and disposal of hazardous substances and wastes' (2017) UN Doc A/HRC/36/41.

43 HRC, 'Principles on human rights and the protection of workers from exposure to toxic substances' (2019) UN Doc A/HRC/42/41 (2019); HRC, 'Report of the Special Rapporteur on the implications for human rights of the environmentally sound management and disposal of hazardous substances and wastes' (2015) UN Doc A/HRC/30/40. 
hazardous substances are handled in accordance with international standards, to take steps to prevent accidents and protect the life of persons under their jurisdiction, including by adequately informing about serious risks. It is safe to assume that had international requirements and basic standards on prevention been adequately implemented, the Beirut port disaster would have been avoided.

\subsection{Failures in Emergency Preparedness and Response}

In addition to adopting measures to handle hazardous substances and prevent accidents, public authorities are required to establish emergency preparedness measures, such as having in place contingency plans that are activated in case of need. International obligations in this area stem in particular from the international treaties mentioned above such as the ILO C174 and from international human rights law. Under the terms of the ILO C174, competent authorities are required to adopt emergency preparedness measures, such as to develop and update emergency plans for the protection of the public and the environment outside each installation (Article 15); to ensure that information on safety measures and on the correct behaviour to be adopted by persons potentially affected is disseminated, that warning is given as soon as possible and, in the event of transboundary impacts, that neighbouring States are informed (Article 16); and to establish a comprehensive policy to distance installations from residential areas and public facilities (Article 17). Preparedness is also covered by the first limb of Priority 4 of the Sendai Framework that provides recommendations on 'Enhancing disaster preparedness for effective response' and puts particular emphasis on the establishment of early warning systems, which should be multi-hazard and people-centred. ${ }^{44}$

These provisions on emergency preparedness were not adhered to by Lebanese authorities and would have significantly contributed to minimising the negative impacts of the explosion. Indeed, from the reports of witnesses of the explosion, it appears that there was no assessment of the danger of the situation when a fire broke out in the vicinity of the storage of ammonium nitrate six hours before the explosion, which occurred around $6 \mathrm{pm}$. Early warnings were not issued to the public potentially affected by the emergency, to emergency relief personnel and health care providers. The report published by Legal Action Worldwide on behalf of the victims affirms that 'the public was never warned about the danger posed by the ammonium nitrate at any stage.

44 For an overview of international obligations relevant to the preparedness phase, see Andrea de Guttry, 'Rules of general scope to be prepared to deal with CBRN emergencies', in de Guttry et al (n 40). 
No evidence was found to suggest that the public was warned once the fire was reported, nor that there were any attempts to evacuate the area: ${ }^{45}$ Bystanders were left filming the fire in close proximity to the blast site for 30 minutes prior to the explosion that left many of them injured or dead. Apparently, first responders were not aware of the type of material stored in the warehouse when they reached the port to respond to the fire: ten fire fighters lost their lives in the explosion. ${ }^{46}$ Similarly, hospitals and emergency response agencies did not receive any notification about a potential catastrophe.

Not only were early warnings not issued but there was a failure to communicate the health risks associated with the explosion, as the public was not warned about the toxicity of the nitrogen dioxide plume released afterwards, which led to severe environmental contamination across the city. International actors such as the IFRC responded to the gaps of the national emergency response framework by organizing awareness-raising campaigns, for both clean-up teams and the general public, urging to wear masks, use thick gloves as protection against shattered glass, wash exposed skin several times a day, remove dust with vacuum cleaners and/or wet towels, and spray water to help particles settle more quickly. ${ }^{47}$ Guidelines and flyers on precautions to be adopted were also issued by the American University of Beirut and the World Health Organization.

UN human rights experts pointed out that people have the right to know the risks of toxic exposure to the hazardous substances released to the air over the city on their health and that 'special attention needs to be paid to older persons, persons with disabilities, and others who may be in particularly vulnerable situations and who are disproportionately affected during emergencies.'48 Recommendations on protecting vulnerable groups during emergency situations are offered to States by UN human rights treaty monitoring bodies in their Concluding Observations and General Comments. ${ }^{49}$ Lebanon is one of few countries in the world, and the only among Arab States, that has not yet ratified yet the Convention of the Rights of Persons with Disabilities (signed in 2007), which enshrines a provision on ensuring specific protection in

\footnotetext{
45 LAW (n 24) 3 .

46 Mazen J. El Sayed, 'Beirut Ammonium Nitrate Explosion: A Man-Made Disaster in Times of the COVID-19 Pandemic' (2020) Disaster Medicine and Public Health Preparedness 1. In the port explosion that occurred in Tianjin, China in 2015, many first responders similarly lost their lives as they were not aware of the stockpile of explosive chemicals contained inside the warehouse.

$47 \quad$ IFRC (n 2O) 6.

48 OHCHR (n 22).

49 Sommario and Venier (n 40).
} 
situation of risk or humanitarian crisis. ${ }^{50}$ In the list of issues sent to Lebanon in November 2020, the Committee on the Elimination of Discrimination Against Women (CEDAW) emphasised the need to take specific measures to ensure the protection of women in the aftermath of the Beirut port explosion, an aspect that will be likely dealt with in the CEDAW upcoming Concluding Observation. ${ }^{51}$ In their replies, sent back in February 2021, Lebanese authorities confirmed that awareness-raising courses were held at seven development service centres for girls and women affected by the Beirut explosion 'in order to give them psychosocial support and spread some basic messages related to gender and protection against gender-based violence. ${ }^{52}$

\subsection{Lack of a Coherent and Comprehensive DRR Framework}

In establishing responsibilities for the Beirut port disaster, Lebanese judicial authorities will have to look at relevant provisions (or the lack thereof) on disaster prevention, preparedness and response as enshrined in different legal acts adopted at the domestic level and at their effective implementation. The fragmentation and gaps of the national legal regime on emergency prevention and preparedness would have been limited by the adoption of a comprehensive DRR legislative and operative framework, clearly setting out responsibilities for risk assessment, hazard identification, and disaster preparedness and response planning, including in terms of notification and early warning, which is still missing in Lebanon. Since 1977, the High Relief Committee established pursuant to Law 22/1977 is mandated with coordinating emergency response, but no authority exists on prevention and risk mitigation. The lack of a dedicated DRR strategy and governance structure is particularly disappointing considering that international projects had been carried out in the DRR field in the last decade which aimed at strengthening the country's risk reduction approach.

Indeed, the lack of a national DRR institution, with a clear mandate and equipped with the necessary financial, technical and human resources, was identified as 'the most important unmet need in Lebanon' by United Nations

50 Convention on the Rights of Persons with Disability, adopted 13 December 2006, art. 11. See also онснв, 'Thematic study on the rights of persons with disabilities under article 11 of the Convention on the Rights of Persons with Disabilities, on situations of risk and humanitarian emergencies' (2015) UN Doc A/HRC/31/30. For a discussion, see Akiko Ito, 'Disasters, International Law, and Persons with Disabilities' in David D. Caron, Michael J. Kelly, Anastasia Telesetsky (eds) The International Law of Disaster Relief (cuP 2014) 208.

$5^{1}$ CEDAW, 'List of issues and questions in relation to the sixth periodic report of Lebanon' (2020) UN Doc CEDAW/C/LBN/Q/6 para 1.

$5^{2}$ Lebanon, 'Replies of Lebanon to the list of issues and questions in relation to its sixth periodic report' (2O21) UN Doc CEDAW/C/LBN/RQ/6, 2. 
Development Programme (UNDP) in $2015 .{ }^{53}$ Between 2009 and 2018, the DRR capacity building project 'Strengthening Disaster Management Capacities in Lebanon' was carried out, under the leadership of the Prime Minister Office with UNDP support, to review the country's institutional and policy framework for DRR and address the main shortcomings. In its first two phases (20102012 and 2013-2015), the UNDP project contributed to the establishment of a Disaster Response and Management (DRM) Unit at the Presidency of the Council of Ministers, the elaboration of a revised National DRR Strategy, the drafting of a law proposal on a National Disaster Management Agency (NDMA), as well as other awareness-raising and training activities. ${ }^{54} \mathrm{~A}$ National Disaster Coordination Committee was created in 2013 pursuant to Decision 41/2013, under the chairmanship of the Secretary of the Supreme Council of Defense, which was mandated to adopt the necessary measures to coordinate disaster response operations.

The third phase of the UNDP project (2016-2018) was concerned with supporting the Government of Lebanon in establishing effective national DRR institutions, in strengthening disaster risk information, and in integrating Chemical, Biological and radio-Nuclear (CBRN) considerations within the national DRR strategies. ${ }^{55}$ However, the law proposal for a comprehensive National Response Plan, that would cover all types of disasters and clarify the roles and responsibilities of major agencies in preparedness, response, and recovery, was not passed by the Parliament and the NDMA was never formed. As indicated by Lebanon in its report on the implementation of the Hyogo Framework for Action in 2015, the establishment of a dedicated national DRR authority 'is a long-term process that necessitates strategic action, legislative action, human resources, and a large amount of funds; most of which are not currently available. ${ }^{56}$

The lack of a comprehensive DRR plan and of a dedicated DRR agency may have significantly contributed to the Beirut port disaster, as the DRR agency would have been the authority responsible for identifying the risk posed by the hazardous material stored unsafely in the port warehouse and for taking any decision on its disposal. Indeed, as indicated in the previous sections, the explosion mainly resulted from the failure to allocate clear responsibilities for adopting the decision on the disposal of ammonium nitrate, despite

53 UNDP, 'Strengthening Disaster Risk Management Capacities in Lebanon - Phase III' (3 November 2015) 10.

54 Ibid. 4.

55 Ibid. $13^{-14}$.

56 Lebanon, 'National progress report on the implementation of the Hyogo Framework for Action (2013-2015)' (23 April 2015) 11. 
its dangerousness was widely known. Furthermore, a comprehensive свRN strategy, covering both intentional and accidental events, and incorporating prevention and response aspects, would have helped in minimizing risks and impacts. That said, it is certain that the prerequisite for the proper functioning of any DRR agency is the availability of good governance mechanisms and of effective anti-corruption legislation and policies.

In any case, having a single entity responsible for risk assessment and mitigation would be particularly needed in those countries where power is shared among multiple actors without clear mandates and with poor accountability mechanisms. Priority 2 of the Sendai Framework on strengthening disaster risk governance confirms the recommendation to 'establish and strengthen government coordination forums composed of relevant stakeholders [...] and a designated national focal point for implementing the Sendai Framework. ${ }^{57}$ Similar considerations were pointed out by the World Bank in its review of the governance frameworks regulating the activities at the port of Beirut, which emphasises that " $\mathrm{t}]$ he governance of the sector is a patchwork of ad-hoc institutions, structures, laws and regulations that preclude the development of a coherent integrated strategy' and inhibit efficiency 'as several key government agencies for transport, trade, and border management have overlapping mandates, divergent strategies, often operate under outdated processes and regulations and do not coordinate among themselves.' ${ }^{58}$ These considerations reinforce the idea that had a single authority been allocated responsibility for DRR measures, the risk of explosion at the port would have been highly mitigated.

In addition to the national DR R framework, measures adopted at the municipal level could have at least partially addressed the main gaps and enhanced protection. The international community recognizes the importance of achieving sustainable, inclusive and safe urban development, as indicated by Sustainable Development Goals 9 on 'Building Resilient Infrastructures' and 11 on 'Sustainable Cities and Human Settlements', as well as by the New Urban Agenda (2016-2036) endorsed by the UN General Assembly in 2017.59 With the adoption of the Aqaba Declaration on Disaster Risk Reduction in Cities, adopted during the 1st Arab Conference on Disaster Risk Reduction held in 2013 in Jordan, local authorities in Arab countries committed to several important actions, such as to set up dedicated local DRR units at the level of municipalities,

\footnotetext{
57 Sendai Framework (n 12) para $27(\mathrm{~g})$.

$5^{8}$ World Bank, 'Reforming and Rebuilding Lebanon's Port Sector. Lessons from Global Best Practices' (2020) 7 .

59 UNGA, 'New Urban Agenda' (2017) UN Doc. A/REs/71/256.
} 
to recommend issuance of legislations and ensure enforcement of laws and regulations aimed at reducing exposure to risks, to allocate between $1 \%$ and $5 \%$ of the budget to DRR measures, to carry out awareness-raising activities, and to setup a municipal early warning committee to prepare and disseminate disaster warning to high-risk communities in urban and rural areas. ${ }^{60}$

Relevant information on Beirut's DRR efforts at the municipal level is not available, and it is not clear to what extent any of the measures proposed in the Aqaba declaration have been actually implemented. We know that in 2018 the Global Facility for Disaster Risk Reduction, a global partnership programme administered by the World Bank launched in 2006 to support developing countries in the implementation of the Hyogo Framework for Action, financed a project on 'Comprehensive Urban Resilience Masterplan for the City of Beirut Phase II'. The project was 'designed to give decision-makers a clear view of the city's shocks and stressors and the specific actions that are needed to address them.' ${ }^{61}$ The main output was a Resilience Master Plan for the city of Beirut, a digital platform to support policy makers diagnose hazards and vulnerabilities and to propose resilience strategies and action plans. ${ }^{62}$ Yet, it is not clear if the platform was actually released in 2020 amid the coviD-19 pandemic, and more importantly if this tool would be able to tackle situations similar to the one that caused the Beirut port disaster (i.e. hazardous material unsafely stored) and to propose any concrete solution to minimise risks. What remains certain are the considerations by the IFRC in the review of its response to the Beirut port explosion, that called for strengthening a community-based disaster response capacity and 'to extend disaster preparedness programmes to local authorities', since it noted that 'municipal authorities in Beirut had very limited knowledge and experience of disaster response' including in terms of 'lack of such basics as proper databases, stakeholder mapping, or evacuation and contingency plans'.63 It would thus be advisable that any investment on DRR measures in Beirut prioritises the basics of risk prevention, preparedness

6o Aqaba Declaration on Disaster Risk Reduction in Cities (21 March 2013).

61 World Bank, 'A Comprehensive Urban Resilience Master Plan for Beirut. A roadmap for a resilient future' (May 2018) 2, <https://www.gfdrr.org/sites/default/files/publication/ Results\%2oin\%2oResilience\%2o-\%2oUrban\%2oResilience\%2oMaster\%2oPlan\%2O in\%2oBeirut\%20-\%2ofinal.pdf $>$. The project details are available at: <https://www.gfdrr .org/en/comprehensive-urban-resilience-masterplan-city-beirut-phase-ii-curmcb-ii>.

62 A presentation of the platform developed for the city of Beirut by the international consultancy firm Buro Happold is available at <https://www.preventionweb.net/files/ 48242_16o315unisdrbhe.pdf>.

63 IFRC (n 20) 15 . 
and response, such as proper hazard identification and adequate emergency planning.

\section{$4 \quad$ International Disaster Law and the Recovery Phase}

Turning our attention to the post-disaster phase, it has to be noted that the recovery phase has not received much attention by international actors and the academic community, despite being recognised as 'the most complex of the disaster management functions, involving the greatest number and variety of stakeholders and affecting the greatest long-term impact on a community's social and economic success'.64 This is particularly the case for contexts such as Lebanon where recovery would need complex structural reforms. This section explores to what extent international (disaster) law is adequately equipped to grant remedies to victims of disasters (4.1) and to provide guidance to support recovery efforts (4.2).

\subsection{Disasters' Victims in Search for Justice}

The right to a remedy is the cornerstone of the legal protection of human rights and is considered to have acquired the status of customary international law. ${ }^{65}$ It comprises procedural rights, such as to have an independent, impartial and transparent investigation, and the substantive right to adequate remedies for the harm suffered. Remedies include restitution (i.e. restoring the victims' condition before the violation, which may comprise rehabilitation of the victims' physical and mental status), compensation (awarded to the victims for pecuniary and nonpecuniary damages and for legal costs), satisfaction (e.g. full and public disclosure of the truth and apologies) and guarantees of nonrepetition (e.g. changes in relevant laws and practices and bringing to justice those responsible). Among the multiple functions of remedies there is indeed the deterrence of similar offences in the future. ${ }^{66}$

Nifosi-Sutton observed that 'State practice confirms that disaster-affected individuals have exercised the core procedural element of the right to a remedy, i.e., the right to lodge complaints before domestic courts [...] in situations where State's negligence in managing a disaster has resulted in violations of

64 UNISDR, 'Build Back Better in recovery, rehabilitation and reconstruction' (UNISDR 2017) 5.

65 Dinah Shelton, Remedies under International Human Rights Law (ou P $\left.2005^{2}\right) 103$.

66 Ibid. 20. 
the rights to life, adequate housing and property' ${ }^{\prime}{ }^{6}$ In the context of hazardous material, the Special Rapporteur on toxic wastes indicated that substantive obligations include remediation of contaminated sites and compensation, provision of physical and mental health care and guarantees of non-repetition. ${ }^{68}$ Both procedural and substantive obligations are of particular relevance to the victims of the Beirut port tragedy. Not only access to justice, rehabilitation and compensation are claimed by those who have been directly affected by the explosion, but establishing the truth and identifying responsibilities, as well as receiving guarantees of non-repetition, are of interest to the Lebanese society as a whole.

As indicated by the Lebanese authorities, some steps were taken to ensure remedies to the victims of the Beirut port blast, including in terms of initiating an investigation and supporting victims' right to access to justice. ${ }^{69}$ The first months of investigation have shown that ensuring justice will not be easy, however. Political leaders have neither assumed responsibility nor acknowledged the causes of the calamity, claiming instead total immunity while asking the removal of the judge who was first appointed. ${ }^{70}$ The lack of independence and impartiality of Lebanese justice system and the frequent violation of due process rules have been pointed out by UN human rights monitoring mechanisms since $1997 .{ }^{71}$ In 2017, the International Commission of Jurists detailed how the provisions relating to the Lebanese High Judicial Council composition, competencies and the guarantees of its independence and impartiality fall short of international standards, and formulated recommendations for amendment and reform. ${ }^{72}$ Independence and impartiality are of course of

67 Ingrid Nifosi-Sutton, 'Contours of Disaster Victims' Rights to a Remedy and Reparation Under International Human Rights Law', in de Guttry, Gestri and Venturini, International Disaster Response Law (Springer 2012) 419.

68 HRC (n 42) 19-21.

69 In addition to initiating investigations, the Lebanese government confirmed for instance that ' $\mathrm{t}$ ] he Bar Association has established a crisis unit made up of volunteer lawyers who provide pro bono legal support to those who have been affected by the explosion that occurred at the port of Beirut on 4 August 2020 and who do not have the financial means to hire a lawyer'. Lebanon $\left(\mathrm{n}_{52}\right) 10$.

70 The Court of Cassation accepted the case brought by former ministers Ghazi Zaiter and Ali Hassan Khalil asking for the removal of judge Fadi Sawan, who had said that he would not stop at the 'red lines' of immunity. See Graham (n 2).

71 Human Rights Committee, 'Concluding Observations: Lebanon' (1997) UN Doc CCPR/C/ 79/Add. $78,14-15$.

72 International Commission of Jurists, 'The Lebanese High Judicial Council in Light of International Standards' (2017). 
particular relevance in case when the judicial bodies have to establish responsibility for negligent acts allegedly committed by public authorities.

The recovery framework proposed by the EU, UN and the World Bank suggests that 'the onus is on Lebanon's justice institutions to deliver services in a more independent, effective, accountable, and accessible manner, particularly to those made more vulnerable by the explosion. ${ }^{73}$ The plan aims at supporting the 'National Human Rights Commission with adequate resources to carry out its mandate to independently monitor the post-blast interventions of stakeholders, safeguard the rights of blast survivors, and identify systemic or widespread issues leading to human rights violations. ${ }^{74}$ It then supports the adoption of the draft legislation that would strengthen the judiciary's independence, and the amendment of relevant provisions of the Penal Code, the Code of Criminal Procedure, and the Law on Judicial Organization 'to empower the judiciary to carry out its mission and shield it from political interference and undue influence. ${ }^{75}$

The victims, however, claim that an international investigative or factfinding mission is required due to the extreme weaknesses of the Lebanese justice system ${ }^{76}$ a call that has been recently supported by the European Parliament. ${ }^{77}$ Lebanon has not recognized the competence of any UN individual complaints mechanisms under international human rights law, and the lack of a regional human rights court means that victims do not have the chance of supranational redress. The prospects of having this case dealt with under the terms of international criminal law are almost non-existent. ${ }^{78}$ The only real possibility, as claimed by the victims, would indeed be to have a factfinding mission or a commission of inquiry mandated to look at allegations of human rights violations in the context of the Beirut port disaster. These missions have gained an increasing relevance over the last years and, although they usually cover the most serious violations of international law, they have

73 EU, UN, World Bank (n 10) 38.

$74 \quad$ Ibid. 38.

75 See the letter sent to the Human Rights Council on 15 June 2021 by Amnesty International and other Non-Governmental Organisations, 'Joint Letter to the Human Rights Council calling for an International Investigative Mission into the Beirut Blast' (15 June 2021) <https://www.amnesty.org/download/Documents/MDE1842842021ENGLISH.pdf>.

76 LAW (n 24) para 123.

77 European Parliament Resolution of 16 September 2021 on the Situation in Lebanon (2021) para 4 .

78 On the threshold and material scope of international criminal law and its weak relevance to disaster situations, see Francesca Russo, 'Disasters Through the Lens of International Criminal Law', in de Guttry, Gestri and Venturini (n 67) 441. 
also addressed human rights protection more broadly. ${ }^{79}$ Furthermore, as indicated by the Office of the High Commission on Human Rights, the mandate of commissions of inquiry can cover one specific event or incident. ${ }^{80}$ The visit of the Special Rapporteur on Toxic Waste, which was requested after the disaster but has not been authorised by Lebanon yet, could shed further light on the violations of victims' rights and could be the first step towards the establishment of such a fact-finding mechanism. We must, however, remain cognizant that there is no example of a similar international mechanism being mandated to investigate negligence in relation to a disaster situation and that the relation of such mechanisms to domestic criminal proceedings is rather complex. ${ }^{81}$

Turning our attention to the different forms of remedies mentioned above, the Sendai Framework touches only upon compensation, when it recommends national authorities 'to promote mechanisms for disaster risk transfer and insurance, risk-sharing and retention and financial protection. ${ }^{82}$ Under the Framework, global and regional actors are called ' $\mathrm{t}$ ] $\mathrm{o}$ promote the development and strengthening of disaster risk transfer and sharing mechanisms and instruments in close cooperation with partners in the international community, business, international financial institutions and other relevant stakeholders' ${ }^{83}$ Insurance risk pools are indeed attracting increased attention as an instrument to ensure liquidity in the aftermath of a disaster. For a pool to be effective, a DRR tool is generally a prerequisite for its establishment to ensure the adoption of adequate prevention and preparedness measures. ${ }^{84}$ International treaty law on liability for industrial accidents could offer an alternative root for compensation, but relevant protocols have not yet been ratified. An example is the International Convention on Liability and Compensation

79 See for instance the International Fact-Finding Mission on the Israeli Settlements in the Occupied Palestinian Territory, which was mandated 'to investigate the implications of the Israeli settlements on the civil, political, economic, social and cultural rights of the Palestinian people throughout the Occupied Palestinian Territory, including East Jerusalem'. HRC, 'Israeli Settlements in the Occupied Palestinian Territory, Including East Jerusalem, and in the Occupied Syrian Golan' (2012) UN Doc. A/HRC/RES/19/17 para 9.

80 OHCHR, 'Commissions of Inquiry and Fact-finding Missions on International Human Rights and Humanitarian Law: Guidance and Practice' (2015) HR/PUB/14/7, 9.

81 Micaela Frulli, 'Fact-Finding or Paving the Road to Criminal Justice: Some Reflections on United Nations Commissions of Inquiry' (2012) 10 Journal of International Criminal Justice 1323 .

82 Sendai Framework (n 12) para $30(\mathrm{~b})$.

$83 \quad$ Ibid. para 31(b).

84 Morten Broberg and Erika Hovani, 'Disaster Risk Reduction through Risk Pooling: The Case of Hazard Risk Pooling Schemes', in Katja LH Samuel, Marie Aronsson-Storrier and Kirsten Nakjavani Bookmiller, The Cambridge Handbook of Disaster Risk Reduction and International Law (CUP 2017) 257. 
for Damage in Connection with the Carriage of Hazardous and Noxious substances by Sea which applies to hazardous substances carried on board a ship as cargo or residues from the previous carriage in bulk of substances and provides for compensation of damage either on board or outside, also through the establishment of an International Hazardous and Noxious Substances Fund. ${ }^{85}$ The Imo recently urged States to ratify and implement the Convention, which would ensure prompt and effective compensation to those who have suffered from damage to person and/or property, including the cost of clean-up and economic losses resulting from the maritime transport of hazardous substances. Considering that the number of ships carrying hazardous and noxious substances is growing steadily with more than 200 million tons of chemicals traded annually by tankers, the Convention would indeed fill an important gap.

\subsection{Recovering from Ashes}

International guidance on recovery, to which the second limb of Priority 4 of the Sendai Framework is devoted, is rather scant. An example of guidance tool to support States in planning their disaster recovery strategies has been offered by the UN Office for Disaster Risk Reduction (UNISDR, now UNDRR), which recommends four tasks, including to develop an all-stakeholder, nationallevel disaster recovery framework; to enable pre-disaster recovery planning among all stakeholders; to formalize processes and systems to enable effective assessment of post-disaster damages and needs; and to institute or strengthen policies, laws, and programs that promote (incentivise), guide (ensure), and support Build Back Better in recovery, rehabilitation, and reconstruction in both the public and private sectors, and by individuals and households. ${ }^{86}$ Among the objectives of the UNDP project discussed in the previous section there was indeed the development of 'capacities to facilitate post crisis recovery of affected communities and sectors' by establishing a national recovery strategy, strengthening capacities to manage recovery in line with the principles of transparency, accountability and building back better, and identifying all stakeholders who could contribute to recovery efforts. ${ }^{87}$ Apparently, no comprehensive recovery framework has been established to date in Lebanon,

85 International Convention on Liability and Compensation for Damage in Connection with the Carriage of Hazardous and Noxious substances by Sea, adopted in 1996 (not yet into force).

86 UNISDR (n 64).

$87 \quad$ UNDP (n 53) 17. 
although the terms of reference on a national strategy for Early Recovery System were drafted in 2014, according to the project's report. ${ }^{88}$

The recovery framework proposed in December 2020 by the EU, UN and World Bank is described as people-centred recovery and reconstruction framework focusing on a period of 18 months that will bridge the immediate humanitarian response and the medium-term recovery and reconstruction efforts to put Lebanon on a path of sustainable development' and guided by the overarching principles of transparency, accountability, and inclusion. ${ }^{89}$ Four strategic pillars are envisaged, including (1) improving governance and accountability; (2) jobs and opportunities; (3) social protection, inclusion, and culture; and (4) improving services and infrastructure. As discussed in section 4.1 above, pillar 1 is relevant to the present discussion as it emphasises the importance of structural reforms in the justice system to ensure that victims of negligence on the part of public authorities have access to justice and to adequate remedies. However, one of the main gaps of this framework is the complete lack of any reference to the urgent need to adopt a national DRR strategy, that would integrate lessons learned from the Beirut port disaster in terms of prevention, preparedness, response and recovery, and foresee the institutional arrangements necessary to ensure its implementation. Furthermore, as a general remark it has to be pointed out that the EU, UN and World Bank framework suggests to be in line with previous diplomatic efforts led by France, which since 2018 aimed at supporting Lebanese economy and institutional reforms, ${ }^{90}$ that were iterated by the Lebanese political leadership several times, but any concrete action has apparently never resulted from these promises. ${ }^{91}$ It remains thus to be seen if this time the country's political leadership will be able to actually implement the requested reforms.

As recently suggested by Eburn, Collins and Da Costa, considering that '[i]nternational law may set high-level goals and reflect consensus but it is only

88 UNDP, 'Strengthening Disaster Risk Management Capacities in Lebanon - Narrative Progress Report' (2015) 11.

$89 \quad$ EU, UN, World Bank (n 10) 14.

90 'Conférence économique pour le développement, par les réformes et avec les entreprises' (CEDRE, 6 April 2018).

91 The Lebanese Center for Policy Studies, 'The Government Monitor No. 16 - The FrenchEndorsed Plan: Rebranding Old Reforms' (LCPS, 14 September 2020) <https://www.lcps -lebanon.org/agendaArticle.php?id=193>. 
with local implementation that effective DRR governance can be achieved, [...] a critical question is not how international law binds states or impacts national governance but how international law impacts on, and can best make a difference to 'local' governance. ${ }^{92}$ With reference to Lebanon, scholars have emphasised that '[s] tarting with the political context - rather than the hazard profile - could help inform new approaches to DRR', and that we must deepen the 'understanding of the relationship between sectarian governance and DRR' ${ }^{\prime 3}$ The analysis carried out in this paper confirms that the Beirut port disaster mainly resulted from a political environment where power is shared but accountability is rarely ensured and that the country is in urgent need of structural reforms, also within the DRR field. To be clear, it is evident that significant reforms that would cover, for instance, anti-corruption legislation, human rights monitoring, and the strengthening of the justice system, are a precondition for any DRR strategy to be effective. In this context, the narrative of resilience is probably counterproductive and misleading, as it prioritises the capacity to absorb shocks rather than the capacity to pursue radical change.

International guidance on DRR can support Lebanon in envisaging a framework that enhances protection against serious risks, through hazard identification and the adoption of risk mitigation and emergency preparedness measures, including in relation to establishing multi-hazard early warning systems as recommended by the Sendai Framework. The development of the Lebanese DRR framework should directly involve different stakeholders and consider the needs and preferences of local communities, with particular attention to vulnerable groups who are likely to be disproportionately affected by disasters. An effective governance structure for its implementation shall be established, with clear enforcement, monitoring and accountability mechanisms. Part of the foreign aid foreseen in the $3_{\mathrm{RF}}$ plan shall be devoted to DRR measures. Furthermore, ad hoc risk mitigation measures must be clearly identified by domestic legislation, in respect of international obligations and recommendations. For instance, the rules on handling hazardous substances enshrined within international treaties and soft law instruments shall be adopted as a basis to establish clear, strict and diligently enforced legislation. This paper has argued that had relevant international provisions on

92 Michael Eburn, Andrew Collins and Karen Da Costa, 'Recognising Limits of International Law in Disaster Risk Reduction as Problem and Solution', in Samuel, Aronsson-Storrier and Navkjavani Bookmiller (n 84) 109 and 127.

93 Katie Peters, Nuha Eltinay and Kerry Holloway, 'Disaster Risk Reduction, urban informality and a 'fragile peace'. The case of Lebanon' (oDI papers 2019) 6. 
prevention been complied with by public authorities in Lebanon, the Beirut port blast would not have occurred. Likewise, if relevant international standards on emergency preparedness and early warning had been followed, the disaster's impacts would have been highly minimised.

Looking at the post-disaster phase, international disaster law seems instead less equipped to guide recovery activities and to ensure that victims have access to adequate remedies and compensation. Recovery has received very small attention by international actors and by the academic community, despite being a very complex phase and having the greatest long-lasting implications. The lack of any reference to victims' rights to a remedy in the context of disasters is an issue that should be more explicitly included in the postSendai DRR framework, and relevant protocols shall be ratified by countries to ensure compensation to the victims of disasters. As the Beirut port explosion demonstrates, the recognition of the victims' suffering before the courts as well as absolute legal accountability of the government are consequential in overcoming a tragic event and in having the chance to fully recover. In Lebanon, the prospects of an impartial and independent investigation, that ensures transparency and participation of victims, are rather poor. International law appears not to have the adequate tools (yet) to support victims' search for justice in disaster contexts, especially when the domestic justice system is not trustworthy and regional or international mechanisms to ensure accountability for human rights violations are not available. 